\title{
La arquitectura de la Seducción: Un análisis de las arquitecturas digitales en la sociedad de consumo
}

\author{
The Architecture of Seduction: \\ An Analysis on Digital Architectures within Consumer Society
}

\author{
JoRGE LEÓN-CASERO \\ Universidad San Jorge (Zaragoza) \\ jleon@usj.es \\ Carlos Cámara-Menoyo \\ Universidad San Jorge (Zaragoza) \\ ccamara@usj.es
}

Recibido: 25 de agosto de 2014

Aprobado: 20 de mayo de 2015

\begin{abstract}
Resumen
Actualmente, las nuevas tecnologías digitales empleadas en arquitectura se están utilizando de forma predominante al servicio de una concepción de la misma como un bien cultural más de la sociedad de consumo. Dentro de este marco cultural neoliberal, la función social de los arquitectos está dejando de ser entendida como la producción de hechos urbanos construidos con vocación de servicio, para pasar a considerarse un eslabón más de la lógica simbólica que rige la producción social de los valores culturales tal como fue definida por Veblen y desarrollada por Baudrillard. Así, el potencial aportado por las nuevas tecnologías digitales de representación, antes que como instrumento dedicado a la pre-verificación del edificio construido, está siendo dirigido hacia dos modelos principales. Por una parte, el desarrollo de arquitecturas puramente virtuales que se configuran de forma exclusiva desde su valor simbólico como "imagen" artística fácilmente reproducible. Por otra, todos aquellos proyectos que, manteniendo todavía la atención a la arquitectura como hecho construido, fundamentan el valor simbólico de las mismas en la imagen de autor y una estética virtual impuesta sobre la materialidad de la arquitectura. La función de servicio social del arquitecto ha entrado definitivamente en un punto de inflexión.
\end{abstract}

Palabras clave: arquitectura digital, Baudrillard, estética virtual, función social del arquitecto, especulación cultural.

León-Casero, J., Cámara-Menoyo, C. (2015): La arquitectura de la Seducción: Un análisis de las arquitecturas digitales en la sociedad de consumo. Arte, Individuo y Sociedad, 27(3) 447-462

Abstract 
Currently new digital tools used in architecture are often at the service of a conception of architecture as a consumer society's cultural good. Within this neoliberal cultural frame, architects' social function is no longer seen as the production of urban facts with sense of duty, but as a part within the symbolic logic that rules the social production of cultural values as it was defined by Veblen and developed by Baudrillard. As a result, the potential given by the new digital tools used in representation has shifted from an instrument used to verify a built project to two different main models: At the one hand the development of pure virtual architectures that are exclusively configured within their symbolic value as artistic "images" easily reproducible. On the other hand the development of all those projects which -even maintaining their attention to architecture as a built fact- base their symbolic value on the author's image and on virtual aesthetics and logics that prevail over architecture's materiality. Architects' sense of duty has definitely reached a turning point. Keywords: digital architecture, Baudrillard, virtual aesthetics, architect's sense of duty, cultural speculation.

Sumario: 1. Del problema teórico: Representación. Consumo. Tecnología. Seducción, 1.1. Representación, 1.2. Consumo, 1.3. Tecnología Digital, 1.4. Seducción, 2. De los efectos prácticos. Arquitecturas virtuales. Estéticas virtuales. Virtualización de lo tectónico, 2.1. Arquitecturas virtuales, 2.2. Estéticas virtuales, 2.3. Virtualización de lo tectónico 3. De las desesperantes, desesperantes conclusiones. Referencias.

Este artículo recoge resultados de la investigación "Mapa de Riesgo Social” financiada por el Ministerio de Economía y Competitividad, Programa de I+D+i orientada a los Retos de la Sociedad, 2013.

\section{Del problema teórico: Representación. Consumo. Tecnología Digital. Seducción}

\subsection{Representación}

De un modo u otro, la consideración simbólico-cultural, tanto de la arquitectura construida como de su mera representación artística, ha acompañado a la disciplina arquitectónica desde sus inicios renacentistas. Ya en el primer libro del De Re Aedificatoria de Alberti se hace referencia a la esencia del hecho arquitectónico como lineamenta, entendiendo por tal no la materialidad tectónica de lo construido sino "la manera en que todos los elementos singulares son dispuestos para componer un todo coherente capaz de formar parte de lo bello y proporcionar una influencia ennoblecedora" (Alberti, 1988, p. 87). Lo cual implica que la esencia del hecho arquitectónico puede observarse tanto en la obra construida como en la representación del mismo, tradicionalmente llevada a cabo a través del dibujo de plantas, alzados y secciones. Ahora bien, desde este punto de vista, existen grandes diferencias entre los conceptos tradicionales de "dibujo" o lineamenta como herramienta de representación, y el moderno de "imagen".

En el caso de la lineamenta, Alberti divide su famoso capítulo en seis partes: Regio (zona), Area (parcela), Partitio (ordenación), Paries (muros), Tectum (cubiertas) y Aperitio (huecos). Es decir, la lineamenta se concibe en función de una utilitas intrínseca a la misma. El principal propósito del dibujo como elemento de representación arquitectónico no es tanto la representación en sí, sino su función como herramienta de composición capaz de re-presentar la lógica estructural de los elementos intervinientes en el hecho arquitectónico, tanto tectónicos como organizativos u ornamentales (sígnicos). El dibujo como instrumento de diseño se identifica, pues, con un proceso de proyección cuya principal intención es ser capaz de "medir" o controlar racionalmente el espacio.

A este respecto, es significativo cómo ya Panofsky consideraba a la perspectiva como 
una herramienta que, por primera vez en la historia de las tecnologías de representación gráfica, conseguía definir el espacio en tanto que un sistema de relaciones básicas de altura, anchura y profundidad. Según Panofsky, con anterioridad a la perspectiva renacentista, "por variadas que fuesen las teorías antiguas del espacio, ninguna de ellas logró nunca definirlo como un sistema de meras relaciones entre la altura, la anchura y la profundidad [...] y la totalidad del mundo permanece siempre como algo fundamentalmente discontinuo". (Panofsky, 1999, p. 27)

Así pues, una vez identificado el objetivo fundamental del dibujo arquitectónico como la medida del espacio "según número, proporción y ritmo justos", era posible que el espectador de la arquitectura reconociera la belleza de un edificio sin que fuera consciente de sus causas racionales de medida del espacio. Una aptitud para captar la belleza entendida siempre como armonía de las relaciones de medida espacial que ya Alberti denominaba cocinnitas. Así pues, el concepto renacentista de cocinnitas englobaba tanto la actividad ordenadora del arquitecto a través del dibujo como la percepción física de dicha ordenación por parte del espectador (Van Eck, 1998).

El problema surge cuando, desde la disciplina estética, la belleza arquitectónica deja de ser comprendida en tanto que efecto directo de las relaciones armónicas de medida del espacio y comienza a difuminarse con el concepto kantiano de "lo sublime" en su aspecto dinámico. Este último, es entendido por Kant precisamente como la imposibilidad de encontrar un concepto en la razón, adecuado a la realidad del fenómeno percibido. Afirma Kant: "Sublime es lo que, por ser sólo capaz de concebirlo, revela una facultad del espíritu que va más allá de toda medida de los sentidos". (Kant, 2005, p. 103). O lo que es lo mismo, el reconocimiento de que hay algo en el fenómeno percibido que está más allá de la razón, concretamente en nuestro caso, más allá de las relaciones de medida introducidas en la esencia del hecho arquitectónico como instrumento de medida del espacio mediante el empleo de las técnicas gráficas de dibujo.

De este modo, pese a los continuados intentos de gran parte de la teoría arquitectónica desarrollada hasta la fecha de seguir considerando el diseño arquitectónico como herramienta de medida y racionalización del espacio, este punto de vista parece que recibió un golpe definitivamente mortal con la exposición Arquitectura Deconstructivista que Mark Wigley y Philip Johnson realizaron en 1988 en el MOMA de New York. Es en el texto que acompaña al catálogo de la exposición donde Wigley defiende cómo el objetivo fundamental de dichas arquitecturas es precisamente "su desafío a la armonía, la unidad y la estabilidad" (Wigley, 1988, p. 11). Concretamente, la consideración del hecho arquitectónico realizado por Wigley y Johnson implica una consideración exclusivamente formal de la arquitectura pero en la que la forma, esto es, la lineamenta, ya no debe ser sometida al criterio de la utilitas o la de instrumento de medida y racionalización del espacio.

En su lugar se alude directamente a una "materialidad constructiva de la forma", afirmándose que "lo que cuenta es la condición del objeto. No la teoría misma. Toda la teoría está contenida en el objeto mismo", concluyendo que "la condición formal del objeto lleva implícita toda su fuerza ideológica"(Wigley, 1988, p. 19). Si a ello unimos que la mayor parte de los proyectos presentados, salvo la casa en Santa Mónica de Frank Gehry, no habían sido construidos, que casi todo el material presentado eran paneles gráficos o fotos de maquetas, y que lo fundamental de los mismos eran simplemente las 
rupturas, des-locaciones, de-flexiones, desviaciones o distorsiones formales realizadas en ellos, vemos cómo la arquitectura es considerada en tanto que manipulaciones gráficas más allá, o más acá, del empleo de dichas herramientas gráficas o representativas como instrumento de medida espacial. Frente al dibujo como herramienta de medida del espacio utilizado a partir de Alberti, aparece aquí el concepto de imagen como instrumento de desmedida y cuyo valor, al no poder ser ya la operación de medida y racionalización del espacio, únicamente puede ser reconstruido desde la consideración simbólica de dicho grafismo como valioso en sí y por sí. Esto es, desde un punto de vista simbólico-cultural.

\subsection{Consumo}

A diferencia de la teoría albertiana del lineamento, según la cual, el valor de la arquitectura se entendía a través de la utilitas y la racionalización del espacio, es decir, a través de un valor de uso primario y fundamental del hecho arquitectónico, la forma de revalorización propia de la sociedad de consumo se caracteriza por una independencia radical de los procesos de valorización de los objetos culturales en ella inmersos respecto a su valor de uso. Si bien Marx ya había sentado en El Capital cómo el valor de cambio, entendiendo por este los procesos de valorización de los objetos y la asignación de precios realizada a través del intercambio mercantil, se realizaba con independencia respecto del valor de uso (de ahí su injusticia o desmedida), siempre consideró la mercancía, en nuestro caso, el objeto arquitectónico, de forma primordial y ontológicamente primera como "un objeto externo, una cosa apta para satisfacer necesidades" (Marx, 1999, p. 3). Es, pues, la materialidad misma de la mercancía "el soporte material del valor de cambio"(Marx, 1999, p. 4). De forma implícita se niega, pues, todo valor de uso a cualquier re-presentación de la arquitectura que no sea un medio útil para la construcción física y tectónica de la misma a la vez que, como fundamento de la misma posibilidad de que dicha arquitectura adquiera un valor de cambio en el mercado, se supone la posibilidad de especular con un valor de uso ya previo: "Detrás de las tentativas de quienes se esfuerzan por presentar la circulación de mercancías como la fuente de la plusvalía se esconde, pues, casi siempre, un quid pro quo, una confusión de valor de uso y valor de cambio". (Marx, 1999, pp. 113-114)

Por su parte, la sociedad de consumo en la que nos encontramos va todavía más lejos al presuponer una inversión fundamental de la lógica marxista de los procesos de valorización. En ella, las prácticas de consumo no tienen sentido si se analizan como hechos individuales y separados unos de otros. Así, tal y como afirma Luis Enrique Alonso, "consumir significa, sobre todo, intercambiar significados sociales y culturales y los bienes/signo que teóricamente son el medio de intercambio se acaban convirtiendo en el fin último de la interacción social" (Alonso, 2009, p. XXXI). El consumo no se define entonces como un simple deseo de propiedad de objetos en virtud de su valor de uso, como todavía sucedía para Marx, sino como una organización manipulada de los objetos, convertidos en imágenes que significan un cierto status o posición social dentro del conjunto. Los "dibujos" de Alberti dejan de tener valor como organización del proyecto y medida racional del espacio para convertirse en "imágenes" re-valorizadas culturalmente en función de su mismo carácter de imagen.

Si bien Veblen ya avanzó en 1899 dicha postura en su Teoría de la clase ociosa 
(Veblen \& Mellizo, 2003) al considerar los fenómenos de consumo como formas de diferenciación y aspiración de los sujetos consumistas, será Baudrillard el primero en avanzar la prioridad del consumo respecto a la misma idea de valor de uso o de necesidad. Desde la perspectiva radical del sociólogo francés, el valor de uso supuestamente subyacente al valor de cambio dado en el mercado o al valor simbólico dado por las relaciones sociales de consumo, en realidad, no es sino consecuencia de los procesos de valorización simbólica. En otras palabras, una imagen de arquitectura deconstructivista puede no tener valor de uso alguno pero, sin embargo, crea una necesidad de consumo motivada por la aspiración a un status social determinado. La arquitectura de marca adquiere de este modo su condición de socialmente hegemónica.

Así, desde este punto de vista, "las necesidades introducidas por la sociedad de consumo son necesarias, no para las personas, sino, sobre todo, para el buen funcionamiento del sistema de signos, según una fórmula autorreferencial" (Alonso, 2009, p. XXXIV). Las necesidades no producen el consumo, el consumo es el que produce las necesidades. En nuestro caso, producir cultura visual. No arquitectura útil funcionalmente. Además de ello, en la sociedad de consumo, hay que producir a los mismos consumidores, hay que producir la demanda misma, y esa producción es infinitamente más costosa que la de las mercancías. A día de hoy, esto es, fundamentalmente, lo que se pide y para lo que se educa a los arquitectos, más allá de resolver problemas técnicos o de vivienda. Su función social aparece reducida a la de catalizadores del proceso de producción simbólico-cultural.

\subsection{Tecnología Digital}

En el ámbito de la representación gráfica, son muchos los cambios tecnológicos que ha vivido la arquitectura desde sus inicios renacentistas hasta la actualidad. Ahora bien, desde el ámbito de la proyección y desarrollo de un proyecto arquitectónico conviene realizar una primera distinción basada en la que ya hicimos entre "dibujo" e "imagen". Así, por una parte estarían todas aquellas tecnologías plenamente implantadas en los medios de producción arquitectónicos y que continuarían estando fundamentalmente orientadas a agilizar y facilitar precisamente el empleo de la representación gráfica como instrumento de medida espacial y de construcción del objeto arquitectónico. Toda una gama de tecnologías que tienen en común el hecho de estar orientadas a la producción de objetos arquitectónicos aún definidos de forma primordial desde su valor de uso concreto y material. Dentro de este ámbito tendríamos, por ejemplo, la utilización masiva del CAD o el BIM (Si bien el CAD es aún una extensión digital de las técnicas de dibujo tradicionales, el BIM en cambio ofrece un nuevo paradigma de trabajo y diseño porque introduce elementos paramétricos e información en forma de bases de datos relacionadas con elementos constructivos, como elementos de diseño y representación. A diferencia de en el CAD, en el BIM no se dibuja elementos constructivos, sino que a partir de elementos constructivos virtuales y paramétricos se "construye" un único modelo del que se extraen distintas representaciones) como métodos de pre-verificación del funcionamiento de la futura obra construida.

Ahora bien, en tanto que categoría opuesta a la llamada arquitectura paramétrica o informacional, es decir, aquella arquitectura cuyo resultado formal resulta de la parametrización de todo tipo de datos e información que son utilizados como herramienta 
de trabajo (Schumacher, 2011), asistimos de forma paralela a un exponencial desarrollo de programas de modelado 3D como 3DStudio, Rhinoceros, Blender o Sketch-up (y de edición de imagen como Photoshop) empleados no tanto para la creación de modelos o prototipos definidos desde su función o valor de uso, sino precisamente como instrumentos de producción de imágenes directamente revalorizadas desde el valor simbólico que adquieren mediante su publicación en los principales mass media culturales del ámbito arquitectónico. Unos avances que, sumados al abaratamiento y popularización del software y hardware utilizados, ha hecho posible la digitalización total del proceso de diseño en todas sus fases. De todos estos avances hay uno que merece una atención especial por su influencia masiva en el cambio de la función social de los arquitectos dentro de la sociedad de consumo: las imágenes sintéticas (infografías o renders).

Si bien la fotografía, e incluso el fotomontaje, venían usándose desde hacía años para complementar a las tradicionales plantas, alzados y secciones, su uso era relativamente restringido debido a los elevados costes económicos y de tiempo del proceso. Además, dado que su expresividad era ciertamente limitada, se utilizaba básicamente para representar el entorno del edificio o, a lo sumo, simular de forma rudimentaria el efecto del edificio acabado. Frente a este uso meramente representativo de la fotografía, las imágenes sintéticas han supuesto una herramienta ideal que va más allá de la posibilidad de mostrar la representación de la obra acabada en su entorno: el hecho de estar totalmente generadas por ordenador implica no tener las limitaciones de la fotografía (Berenguer, 1991) y, por tanto, no permanecer ligadas únicamente a la representación, sino a la creación o simulación plena de espacios completamente virtuales ajenos por entero a las necesidades del mundo material.

A partir de este momento, las imágenes sintéticas (los renders) se integran en el proceso proyectual como formas de creación autónomas, ya no destinadas al proceso de pre-verificación de espacios, de iluminación o de materiales antes de que éstos sean construidos, sino, tal y como la sociedad de consumo determina, como producción directa de procesos de valorización de la propia imagen. Y es precisamente en su calidad de imagen independiente del proceso constructivo donde la imagen sintética encuentra su capacidad de singularización y de creación de marca. Nace entonces un nuevo lenguaje propio que por primera vez pasa de ser eminentemente gráfico a ser multimedia, debido a su potencial incorporación de elementos como vídeos, animaciones e incluso realidad virtual y/o realidad aumentada (Moya, 2010). Un nuevo lenguaje que permite singularizarse como creador a la búsqueda de su imagen-marca. Tanto es así que existen grupos de investigación como el de EDPA - L'Expressió del Projecte d'Arquitectura. Anàlisi i Evolució (Universitat de Catalunya) y de tesis doctorales sobre arquitectura y representación como la de Laura Lopes (Lopes, 2008). Tal y como la sociedad de consumo dicta, lo que en principio comenzó siendo un medio para conseguir algo con mayor eficacia (ya sea un render, un sistema informacional, un proceso de trabajo) ha pasado a ser el fin último. Así, la generación de un buen render, que en un principio se utilizaba como verificación o representación de una realidad todavía no material, pasa a convertirse en la auténtica finalidad del proyecto.

\subsection{Seducción}


De la confluencia de los procesos de valorización de la sociedad de consumo con las nuevas técnicas, ya no tanto de representación como de simulación de la realidad, empleadas de forma masiva en el diseño arquitectónico emerge lo que podríamos denominar, en honor a Baudrillard, el actual sistema de la arquitectura de la seducción. Esta, en palabras del propio Baudrillard, es considerada precisamente como "aquello que no tiene representación posible, porque la distancia entre lo real y su doble, la distorsión entre el Mismo y el Otro está abolida" (Baudrillard, 1981, p. 67). La arquitectura de la seducción no seduce por su valor de uso, ni siquiera por la mediación que la representación supone entre el modelo simulado y el futuro potencial construible, sino por la generación de simulacros en cuanto tal como productos en sí capaz de revalorizarse socialmente. Ya no hay modelos y edificios, sino únicamente imágenes. La arquitectura es, pues, un proceso de simulación, de construcción de lo real en cuanto virtual. La arquitectura de la sociedad de consumo es puro simulacro, "es decir, el efecto de verdad que oculta que esta no existe" (Baudrillard, 1981, p. 39). La arquitectura ya no construye. Simplemente simula construir. O construye simulacros. Es desde esta posición que pasamos a analizar tres prácticas actuales que, desde nuestro punto de vista, definen la arquitectura de la seducción:

1. El desarrollo de proyectos concebidos exclusivamente desde y para el espacio virtual que permiten las nuevas tecnologías de simulación, a los que hemos llamado "Arquitecturas virtuales".

2. La generación de una nueva estética virtual, esto es, producida autónomamente desde las capacidades que las nuevas tecnologías digitales de modelado y simulación son capaces de generar, con el consecuente problema de traducirlo posteriormente a sistemas constructivos tectónicos.

3. Los procesos de virtualización de arquitecturas construidas, ya sea a través de la pérdida progresiva del carácter tectónico de los materiales, como de la consideración multimedia del espacio construido.

\section{De los efectos prácticos: Arquitecturas virtuales. Estéticas virtuales Virtualización de lo tectónico}

\subsection{Arquitecturas virtuales}

Como hemos visto, en la tradición arquitectónica no solo ha habido lugar para la arquitectura construida. Existe también un grupo de arquitecturas sin vocación tectónica únicamente existentes en la virtualidad de sus representaciones, ya sea en forma de planos, croquis, maquetas o, ya en la actualidad, imágenes sintéticas. Desde las obras de Massacio o Piero della Francesca a las arquitecturas utópicas de Boullée o Ledoux, pasando por las cárceles de Piranesi, y hasta las utópicas urbatecturas de Archigram o Superstudio, la arquitecturas virtuales de finales de siglo XX y principios del XXI suponen un crecimiento cuantitativo exponencial de proyectos acordes con esta visión de la función social del arquitecto como productor de imágenes simbólicamente revalorizadas.

Tanto es así que, en la actualidad, existen arquitectos más conocidos por sus arquitecturas virtuales que por las que han llegado a materializar, como es el caso de 
WAI Think Tank con sus Narrative architectures, las arquitecturas a construir de Luis de Garrido o la Dynamic Tower de David Fisher. Incluso arquitectos con una trayectoria y obra construida contrastada también han dado un paso hacia este tipo de arquitecturas. Tal es el caso de Rem Koolhaas en Exodus (Koolhaas, 1998) y su polémica afirmación "la arquitectura es una ficción" (Wainwright \& Levene, 2014), muchos de los proyectos de Vicente Guallart (especialmente en su etapa en Metápolis), Norman Foster con su estudio sobre asentamientos en el Polo Sur de la Luna (Fernández-Galiano, 2013b, p. 324) o Peter Eissenman y su Virtual House (Eisenman, 1999).

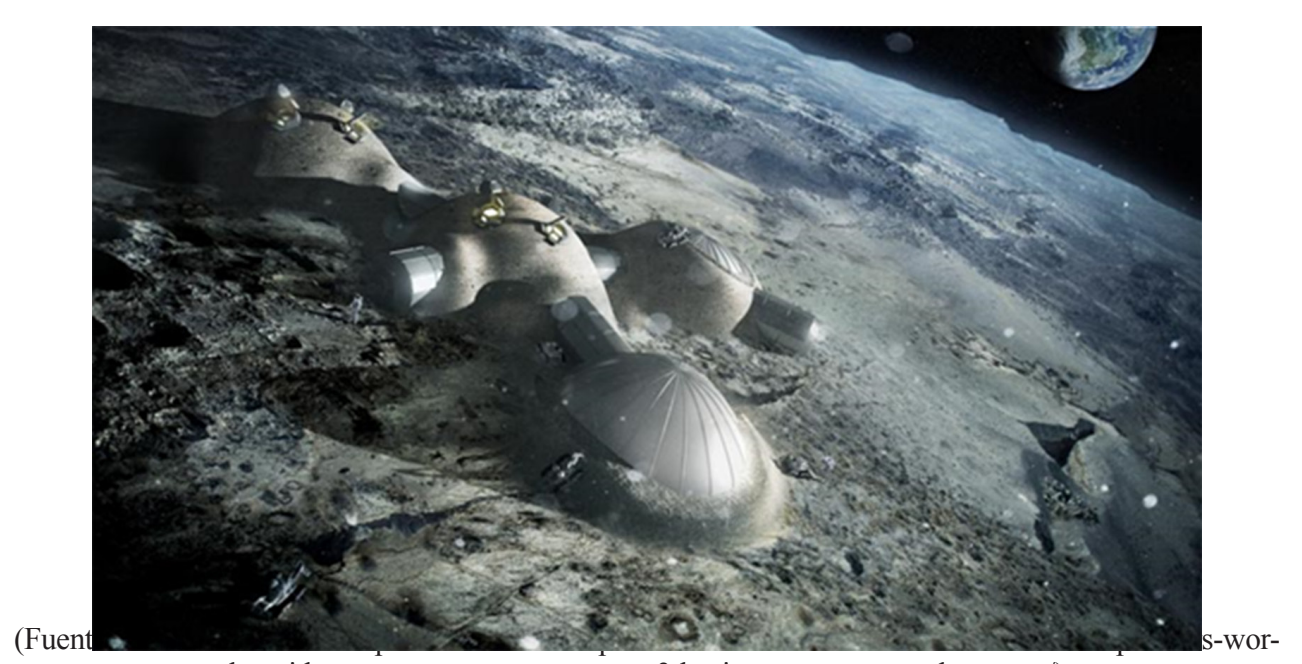

ks-with-european-space-agency-to-3d-print-structures-on-the-moon/)

Así pues, es necesario ir más allá de esta sucinta definición inicial para poder realizar un análisis más minucioso que nos permita distinguir dos grandes grupos de "arquitecturas virtuales": el primero, ejemplificado en las propuestas de Boullée, Friedman o WAI, englobaría aquellas arquitecturas digitales realizadas como ejercicio reflexivo sobre la propia arquitectura, su composición y construcción (teoría del proyecto), mientras que el segundo, formado, entre otros, por la falsa casa en forma de campo de fútbol para el futbolista Lionel Messi de Luis de Garrido («MIRA», 2013; Redacción, 2013a, 2013b, 2013c) o la propuesta de rascacielos giratorio de David Fisher (Young, 2001) incluye aquellas realizadas como ejercicio meramente formal o de marketing.

Resulta crucial realizar esta diferenciación ya que en los ejemplos del primer grupo puede apreciarse un principio de linamenta, al tratarse de mecanismos intelectuales con voluntad de investigación compositiva como técnica de control y racionalización del espacio. Este hecho tan significativo las convierte en arquitecturas mucho más próximas a las arquitecturas utópicas sobre el papel del siglo XVIII de Ledoux o Boullée en su intención de ordenar el mundo y la sociedad futura según los ideales de la Ilustración a través de la pureza y racionalidad de sus formas e ideales. Este fenómeno es algo que no existe en los ejemplos del segundo grupo, totalmente ligado al concepto moderno 
de "imagen" que enunciábamos con anterioridad, ya que están totalmente desprovistos de cualquier voluntad más allá de la generación de formas sorprendentes por el simple hecho de que la informática permite calcularlas, traduciéndose por tanto en objetos de consumo reconocibles en primer lugar como "arquitectura".

Así pues, si esas arquitecturas en papel del siglo XVIII siempre tenían de fondo la construcción en el futuro de un mundo utópico, igualitario y cuasisocialista según los ideales de la Ilustración, las imágenes de este grupo, si es que reflejan alguno, son, como mucho, los del neoliberalismo. Se trata pues, de ideologías completamente contrarias: en el XVIII se quería organizar, medir y racionalizar un nuevo mundo a través de la arquitectura, mientras que en el XXI el objetivo es venderla como arte y que se revalorice en el mercado.

\subsection{Estéticas virtuales}

Por otra parte existe otro grupo de arquitecturas que comparten con las denominadas “arquitecturas virtuales" una estética futurista, más próxima a la arquitectura de cómic o de cine que, a pesar de la aparente similitud con éstas, sí que tienen vocación -o cuanto menos posibilidad- de ser construidas. Es precisamente este hecho crucial lo que resulta definitorio de este grupo, pues implica estar sujeto a los condicionantes morfológicos, técnicos, económicos, legales o culturales que existen en el mundo físico y que no existen en entornos digitales. Sin embargo, y a pesar de ello, el proceso de construcción o ejecución no se suele tener en cuenta durante las fases de diseño, lo cual no deja de ser sorprendente a la vez que significativo. Motivo por el cual las consideramos como un subgrupo de las arquitecturas digitales con entidad propia.

Si bien es habitual la utilización de renders, fotomontajes, vídeos, maquetas y cualquier otro medio que permita experimentar, poner a prueba y hacer evolucionar el proyecto antes de que éste sea construido (con las consecuentes dificultades que supondría hacerlo en esta fase), las arquitecturas a las que nos referimos en este apartado no reflejan ningún tipo de evolución en el proyecto a través de la aparición de nuevos matices y detalles debidos a la incorporación de nuevos inputs en la fase de proyecto, y sobre todo de los imprevistos inherentes a cualquier ejecución en obra

A este respecto resulta paradigmático el caso de la obra de Jurgen Mayer, conocida como Metropol Parasol, en la plaza de la Encarnación de Sevilla. A pesar de que la silueta general de la imagen sintética del concurso realizado en 2004 es casi idéntica con la del objeto que se acabó construyendo en 2011, un mínimo análisis demuestra que el sistema constructivo es totalmente diferente, lo cual explicita cuáles fueron las prioridades del proyecto: la forma exterior estaba clara a pesar de que no se sabía cómo construir (no parecía ser importante en ese momento a pesar de su evidente complejidad técnica). Detalle que se tradujo en un retraso de más de 5 años, un aumento del presupuesto inicial en más de un $72 \%$ e incluso un polémico informe de la empresa OVE ARUP en relación a su viabilidad técnica (AAVV., 2011). 

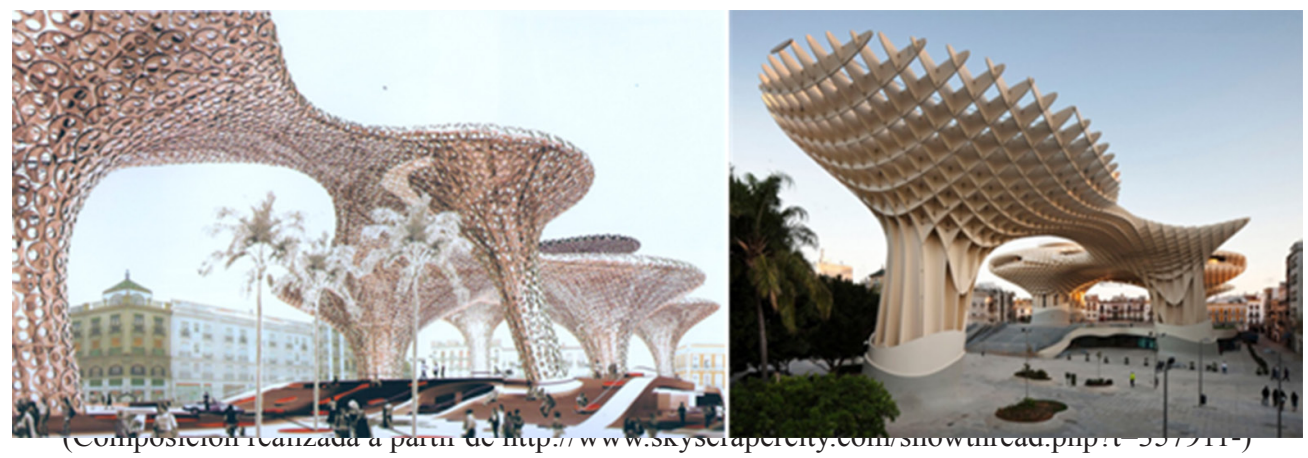

El caso del teatro de Torrevieja, Obra de FOA, muestra también una gran similitud entre proyecto y obra terminada, salvo por el hecho de que, contrariamente a lo que suele ocurrir, el render tiene más detalle que la realidad construida, tal y como puede apreciarse claramente en la fachada.
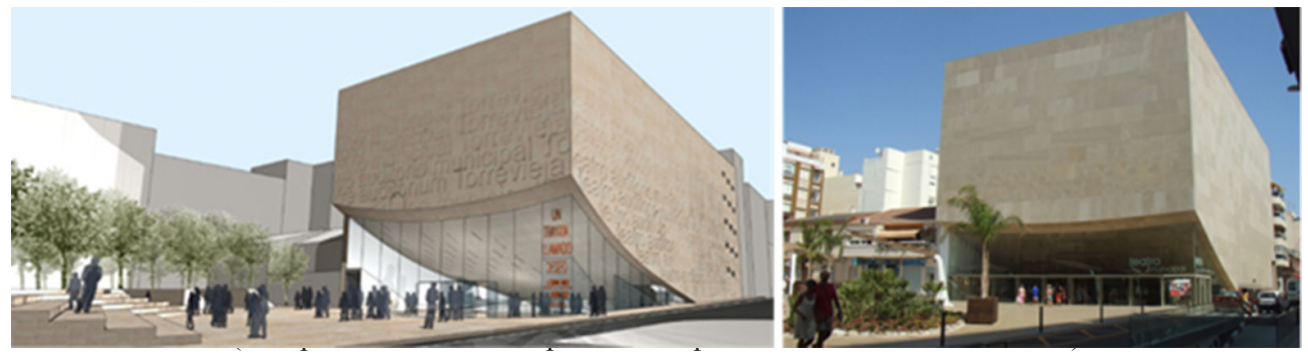

Hay también casos de arquitecturas falsamente construibles, que ni siquiera parecen verse afectados por las reglas tan básicas y mundanas como las de la física que rigen los mundos conocidos, como el caso de The Stocholm Sphere Masterplan(FernándezGaliano, 2011), realizado por el estudio BIG. En este ejemplo los renders realizados por el estudio muestran sin ningún tipo de pudor una esfera reflectante gigantesca que se eleva en el aire sin ningún tipo de estructura visible- No parece importar el hecho de que sea imposible construir algo así o que la solución final diste mucho de este efecto, ni tan siquiera cuando es el elemento central del proyecto y el que le da nombre. 


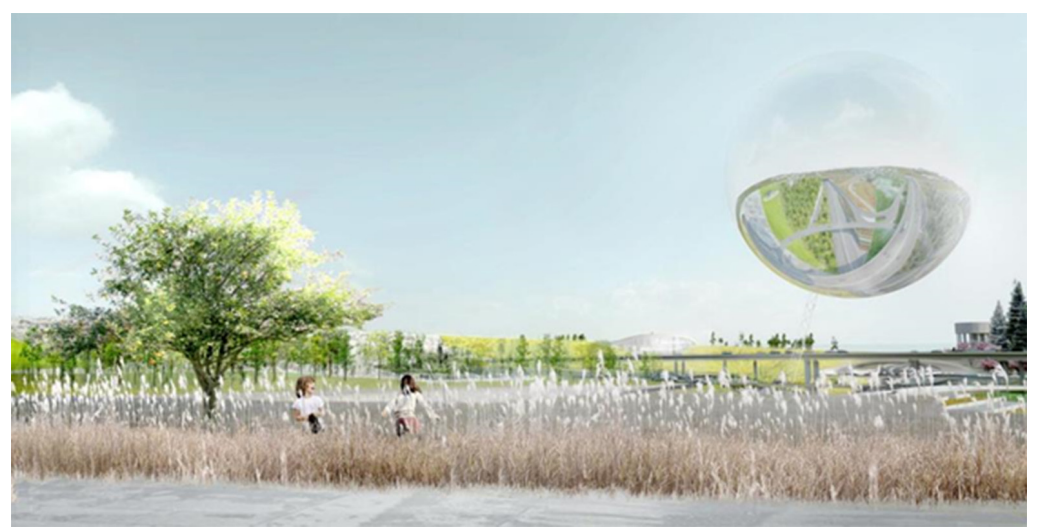

Una vez llegados a este punto es importante recalcar la diferencia que existe entre no saber construir algo en el momento de realización del proyecto, y el hecho de saber que nunca se podrá construir de esta forma. En el primer caso estamos ante el concepto de "transducción" defendido por Lefebvre a lo largo de Mayo del 68 (Lefebvre, 1969, p.129). En el segundo, en el propio de lo que denominamos la arquitectura de la seducción. Mientras que el primer caso exige un proceso de investigación que no termina con el render o la realización del proyecto de arquitectura, el segundo caso es claramente una ficción para seducir. Así pues, el hecho de que sea tan fácil, rápido y económico generar imágenes sintéticas desligadas de cualquier restricción ha introducido un nuevo ritmo a la arquitectura, que ha pasado de ser algo muy lento debido a su naturaleza reflexiva y a la propia construcción a ser un fenómeno de generación y consumo rápidos ligado a las modas. La disciplina arquitectónica es finalmente reducida a una mera moda estilística hasta el punto de que "la construcción de algunos de esos proyectos concebidos digitalmente, pone de manifiesto la inmadurez arquitectónica de sus autores" (Massad \& Guerrero Yeste, 2009).

Todo ello no hace sino evidenciar que existe una preferencia por lo virtual frente a la realidad tectónica, prefiriéndose en muchos casos las imágenes sintéticas del proyecto a lo que acaba siendo la realidad construida. Ejemplos de ello los encontramos en arquitectos como Rudy Ricciotti, en cuya web oficial (Ricciotti, s. f.) presenta su Salle de Musiques Actuelles en Metz a partir de numerosas imágenes sintéticas y una única fotografía de un detalle de la fachada, a pesar de que el edificio está terminado de forma bastante fidedigna al render de la propuesta, o en muchas de las obras de los ya mencionados BIG, como la piscina y baños termales en el puerto de Copenhague (Fernández-Galiano, 2013a, p. 19 , donde se muestra un montaje en el que puede apreciarse cómo se han eliminado las barandillas). En ambos casos se trata de obras terminadas, pero sus autores prefieren utilizar imágenes sintéticas o fotomontajes que maquillan la realidad construida frente a fotografías reales para difundir los proyectos, ya sea en sus webs oficiales respectivas o en medios especializados.

\subsection{Virtualización de lo tectónico}

Paradigma de los cambios sufridos por la arquitectura en la propia obra construida 
son las nuevas tipologías que están inundando la producción arquitectónica actual: los showrooms. Considerados de forma primordial como "monumentos habitables de marca" la función principal de los showrooms, más allá de un valor de uso en extremo etéreo y maleable de mero contenedor de personas para el más variado y amplio catálogo de acciones, consiste en ser imagen singular de una concreta entidad, pública o privada.

A este respecto, marcas globales como Prada, Apple, Roca, Citroën o Dior tienen el protocolo de encargar a arquitectos estrella la construcción de sus showrooms en ciudades globales como Nueva York, Tokio, Paris, Londres Madrid y Barcelona. Ejemplos paradigmáticos de ello son el encargo de Prada a OMA para sus sedes de New York, Los Ángeles, San Francisco y Venecia, a Herzog \& de Meuron para su sede de Tokio y a Sanaa para su sede en Hong Kong; el de Citroën a Herzog \& de Meuron para su showroom de París, el de Dior a Sanna en Omotesando (Japón), o la sede que hizo Foster \& Partners para Apple en Cupertino.

En tanto que en realidad se trata de un subgrupo actualizado de arquitectura icónica, los showrooms no son espacios al uso sino complejos lugares a medio camino entre la tienda y la sala de exposiciones, entre lo comercial y lo cultural. Los productos se exhiben como en una exposición y se acompañan a menudo de actividades culturales de todo tipo, ligando cultura con mercado. Fundamento principal en el que se basan este tipo de construcciones es el concepto anteriormente explicado de seducción, de modo que para que esta se produzca no basta con exponer productos: es necesario provocar una experiencia estética superior, "sublime", y en ello las nuevas arquitecturas digitales juegan un papel determinante.

Uno de los primeros ejemplos fue el realizado por el teórico y creador de tendencia Rem Koolhaas para Prada en Nueva York en 2002, hasta el punto de afirmar que es con dicho proyecto con el que podemos datar el nacimiento de esta nueva tipología. Tal y como puede apreciarse a partir de lo que decía la prensa especializada tras su inauguración: "Durante una semana la tienda estuvo llena todo el día. Curiosos que iban a comprobar el 'nuevo concepto' de compras inundaron cada recoveco de un espacio que parece no llenarse nunca. Y, desde luego, el ambiente era todo menos una tienda. Todo el mundo tocando cada material, cada esquina, cada máquina; explorando un terreno desconocido y difícilmente asimilable a otras experiencias consumistas. ¿Y la ropa? No se sabe. Nadie se fijó en ella. Porque pasando a ser la sede, la tienda tiene como misión fundamental la venta de su imagen" (Calvillo, 2002).

La mayoría de características definitorias de esta tipología se derivan de su condición híbrida ligada al consumo pero también a la cultura, como por ejemplo el lujo en los materiales utilizados así como de los espacios creados, unos espacios capaces de albergar a grandes cantidades de personas que deberán promover la cómoda contemplación de los productos que allí se expongan a modo de obras de arte. Es este binomio el encargado no solo de transmitir las sensaciones y sentimientos asociados a la marca sino también de ofrecer una experiencia cuasi-mística que cree la ficción de poder vivirse de forma similar mediante la adquisición de sus productos.

El uso de la tecnología, tan ligada a la innovación, suele ser otra constante. Así, la experimentación con nuevas tecnologías o con usos innovadores de tecnologías existentes pasa a estar integrada en la propia definición del proyecto, sin que se trate de añadidos $a$ posteriori. Tal y como ocurre con gran parte de productos en los que el envoltorio forma parte crucial del éxito del mismo, las fachadas de los showrooms también adquieren un 
rol importantísimo, pues como si de packaging se tratase, son las encargadas de atraer a gente hacia su interior y de ofrecer la imagen visible que permita reconocer fácilmente el edificio y asociarlo a la marca. Finalmente, y aunque estrictamente no haya relación directa con la definición del proyecto arquitectónico, no puede obviarse el hecho de que muchos de ellos complementan su actividad cotidiana con una activa agenda de eventos culturales de todo tipo (debates, exposiciones, etc.) que terminan de conformar su identidad deleuzianamente esquizofrénica pero baudrillardianamente seductora.

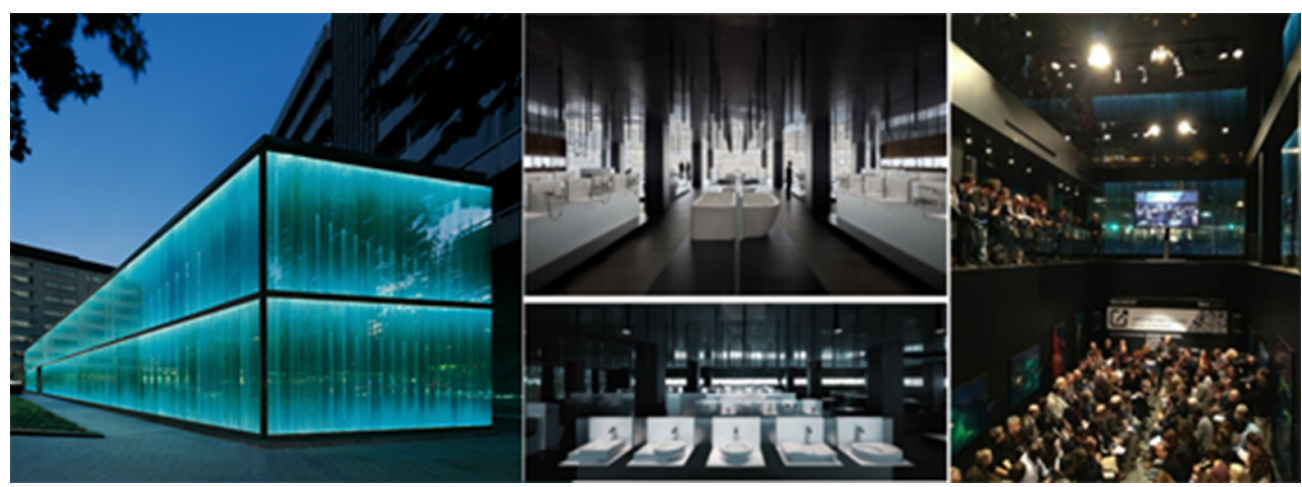

En el caso de la Roca Gallery de Barcelona, obra de Carlos Ferrater, vemos todo esto reflejado ya desde la propia fachada de vidrio coloreado puesto de canto, cuyos colores (especialmente cuando se ilumina por la noche) y reflejos deformados de los alrededores, los vehículos y los peatones que circulan por sus cercanías, terminan provocando un curioso juego visual que actúa de reclamo y entretenimiento. Ya en su interior puede apreciarse un gran espacio vacío que suele hacer las veces de lugar expositivo y de encuentro para debates en función de su apretada agenda cultural así como una zona en la que pueden contemplarse los productos de la marca de manera similar a lo que se haría con un cuadro o una escultura. Las pantallas integradas en las paredes ofrecen interactividades multimedia que, junto con la iluminación, reaccionan con la presencia y movimientos de los visitantes. Todos estos mecanismos y recursos no son añadidos $a$ posteriori sino que fueron concebidos desde las primeras fases del proyecto, lo cual no hace sino evidenciar la importancia que juegan en la obra final, en la contribución a la estimulación y seducción del visitante, transformándolo en espectador y posteriormente en "evangelizador" y cliente de la marca.

Dicha tipología del showroom evidencia algo que, no podemos obviar: el hecho de que la arquitectura siempre haya estado ligada al poder (Sudjic, 2007) y que actualmente éste esté representado por el sector privado, y más concretamente por entidades bancarias y empresas transnacionales. Por este motivo no debe sorprender el hecho de que muchas de estas marcas hayan querido asociarse a archistars, así como de que también hayan florecido en los últimos años arquitectos especialistas en showrooms para transnacionales. Un caso claro de esta especialización es el de la firma de arquitectura 
Bohlin Cywinski Jackson, que ha realizado 14 showrooms para Apple repartidos entre EEUU, Reino Unido, Australia, Japón y Francia, un showroom para Uniqlo y sedes para Adobe y Pixar.

\section{De las desesperantes, desesperantes conclusiones}

Como hemos intentado evidenciar, uno de los empleos primordiales de las nuevas arquitecturas digitales por parte de la sociedad de consumo, es su consideración unilateral de productos orientados directamente al mercado cultural, de forma que las nuevas tipologías generadas son concebidas no tanto para ser usadas (por su valor de uso) como para ser consumidas (su valor de cambio simbólico en la sociedad). Paradójica consecuencia de todo ello es que en su afán por seducir, este tipo de arquitectura tan propia de la sociedad del consumo ha quedado seducida por la propia seducción, perdiendo su sentido originario de función social y acercándola más hacia campos meramente cultural-especulativos.

Ahora bien, es importante ser capaces de percibir cómo esta seducción de la arquitectura misma por el consumo no es simplemente un mero cambio de ideología respecto a la función social y rol profesional de los arquitectos respecto a la sociedad. "El sentido fundamental del consumo consiste en comprender que hay un auténtico terrorismo del signo que funciona de manera totalitaria. En el sentido de que es él y sólo él el que tiene eficacia" (Alonso, 2009, p. XLVII). Y la arquitectura, en tanto que parte estructural de la nueva sociedad de consumo, lo quieran o no los arquitectos que la ejercen, no puede sino funcionar estructuralmente como agente al servicio directo del totalitarismo del signo.

Podemos encontrar tres grandes motivos que han hecho posible el nacimiento de estas nuevas arquitecturas sígnicamente "totalitarias" del siglo XXI: Por un lado los avances tecnológicos y el abaratamiento de los mismos han promovido que la manipulación digital sea algo cotidiano y que posibilita hacer este tipo de arquitecturas con costes y tiempos relativamente bajos (al menos si lo comparamos con lo que costaban anteriormente). Por otro, a la coyuntura económica y laboral de la arquitectura que exige una producción seductora a ritmo frenético para poder competir en los numerosos y superpoblados concursos de arquitectura que actúan como principal, y casi única, puerta de acceso al encargo profesional. El tercero, derivado de la confusión entre cultura y espectáculo, se traduce en la falta de cualquier otra lectura que no sea la del punto de vista del propio render y la facilidad de transmisión de información en medios digitales. Esta difusión tan profusa, a su vez, favorece un revuelo mediático entre medios de comunicación, tanto especializados como generalistas, del que únicamente salen beneficiados los autores, los medios que los difunden y los políticos o directivos que las consumen, esperando sacar partido de dichas imágenes. Nunca la sociedad en su conjunto.

Como hemos argumentado a lo largo del artículo, estos hechos se traducen en la creación de un nuevo tipo de arquitecturas cuya motivación, no es ya la reflexión o la investigación (a fin de cuentas ni hay tiempo para ello ni nadie lo ha pedido), y en algunos ni tan siquiera la propia construcción (y por tanto de las consecuencias sociales, urbanísticas y morfológicas que se derivan de ella), sino que únicamente tienen que ver con la creación de un nuevo lenguaje expresivo en la ya colmada y sobre-estimulada 
estructura cultural de la moda.

Por último, dicha arquitectura de la seducción, al re-configurarse como uno de los nuevos ámbitos de distinción social y/o imagen corporativa "no puede prescindir de un despilfarro festivo [...] no puede más que devorar, de algún modo vergonzosamente, su exceso de riqueza, practicando una destrucción calculada complementaria del cálculo de productividad" (Baudrillard, 2009, p. 29 Nota al pie 2). Ahora bien, si por una parte es cierto que dicha "economía del despilfarro" siempre ha estado de una forma u otra en toda relación socioeconómica, no es menos cierto que por otra, dicho gasto suntuario "siempre es prerrogativa de una minoría privilegiada y cumple precisamente la función de reproducir el privilegio de casta o de clase" (Baudrillard, 2009, p. 44). En última instancia, el nuevo empleo de las tecnologías virtuales que emplea la arquitectura de la seducción se configura como un totalitarismo lingüístico al servicio directo de la alta burguesía en el poder.

Por nuestra parte, tanto a modo de investigadores como de arquitectos, defendemos abiertamente una concepción de servicio útil y material de la función social del arquitecto. A este respecto, todos los proyectos de investigación incluidos en el grupo de investigación Arquitecturas Open Source, incluido el Mapa de Riesgo Social en el que se enmarca el presente artículo, no buscan otra cosa. Ahora bien, antes de proceder al desarrollo sistemático y riguroso de dichos proyectos con vocación de servicio social, nos ha parecido oportuno reflexionar primero sobre el actual contexto cultural, económico e ideológico-académico en el que se inserta la labor efectiva de arquitectos e investigadores como paso previo al inicio de la lucha contra el empleo neoliberalsimbólico de las nuevas tecnologías. Larga vida al valor de uso social de la tecnología Open Source.

\section{Referencias}

AAVV. (2011). Metropol Parasol de la Encarnación. En Wikipedia, la enciclopedia libre. Recuperado a partir de http://es.wikipedia.org/wiki/Metropol_Parasol_de_la_ Encarnaci\%C3\%B3n

Alberti, L. B. (1988). De re aedificatoria. On the Art of Building in Ten Books. (J. Rykwer, N. Leach, \& R. Tavernor, Trads.). MIT Press.

Alonso, L. E. (2009). Prefacio. En La sociedad de consumo: Sus mitos, sus estructuras. Siglo XXI de España Editores.

Baudrillard, J. (1981). De la seducción. Madrid: Catedra.

Baudrillard, J. (2009). La sociedad de consumo: Sus mitos, sus estructuras. Siglo XXI de España Editores.

Berenguer, X. (1991). Las imágenes sintéticas. Temes de Disseny, (5). Recuperado a partir de http://www.upf.edu/pdi/dcom/xavierberenguer/textos/sint/sintetc.htm

Calvillo, N. (2002, febrero). El lujo según OMA/Rem Koolhaas. Pasajes de Arquitectura y Urbanismo, 4(34), 4-7.

Eisenman, P. (1999). Diagram Diaries. London: Thames \& Hudson.

Fernández-Galiano, L. (Ed.). (2011). Dossier BIG. Madrid: Arquitectura Viva SL.

Fernández-Galiano, L. (Ed.). (2013a). BIG - Bjarke Ingels. Madrid: Arquitectura Viva SL. 
Fernández-Galiano, L. (Ed.). (2013b). Norman Foster in the 21st century. Madrid: Arquitectura Viva SL.

Kant, I. (2005). Crítica del juicio. (J. Rovira Armengol, Trad.). Buenos Aires: Losada.

Koolhaas, R. (1998). S, M, L, XL. New York: The Monacelli Press.

Lefebvre, H. (1969). El derecho a la ciudad. Barcelona: Ediciones Península.

Lopes, L. (2008). Arquitectura y representación: Álvaro Siza y Enric Miralles (Tesis doctoral). Universitat Politècnica de Catalunya, Barcelona. Recuperado a partir de http://tesis.com.es/documentos/arquitectura-representacion-alvaro-siza-enricmiralles/

Marx, K. (1999). El capital I: crítica de la economía política. (W. Roces, Trad.). México: Fondo de Cultura Económica.

Massad, F., \& Guerrero Yeste, A. (2009). El proyecto de la visión. Exit, (36), 16-24.

MIRA: La lujosa mansión de Messi en forma de balón (VIDEO). (2013). Recuperado 20 de mayo de 2014, a partir de http://voces.huffingtonpost.com/2013/10/03/lionelmessi-casa-balon_n_4039061.html

Panofsky, E. (1999). La perspectiva como «forma simbólica». Barcelona: Tusquets Editores.

Redacción. (2013a, octubre 3). El diseño futbolero de la nueva casa ofrecida a Messi. MARCA. Recuperado a partir de http://www.marca.com/2013/10/03/futbol/equipos/ barcelona/1380803896.html

Redacción. (2013b, octubre 3). La casa balón de Messi. La Vanguardia. Recuperado a partir de http://www.lavanguardia.com/gente/20131003/54388373056/casa-balonmessi.html

Redacción. (2013c, octubre 3). Lionel Messi: Diseñan casa en forma de balón y cancha de fútbol para la estrella argentina (VIDEO). HuffPost Voces. Recuperado a partir de http://voces.huffingtonpost.com/2013/10/03/lionel-messi-casa-balon_n_4039061. html

Ricciotti, R. (s. f.). Salle de Musiques Actuelles. Recuperado a partir de http://www. rudyricciotti.com/culturels/salle-de-musiques-actuelles.html

Schumacher, P. (2011). The autopoiesis of architecture a new framework for architecture. Chichester: Wiley.

Sudjic, D. (2007). La arquitectura del poder : cómo los ricos y poderosos dan forma al mundo (1a ed.). Barcelona: Editorial Ariel.

Van Eck, C. (1998). The Structure of De re aedificatoria Reconsidered. JSAH, 57(3), 280-297.

Veblen, T., \& Mellizo, C. (2003). Teoría de la clase ociosa. Madrid: Alianza Editorial.

Wainwright, O., \& Levene, D. (2014, junio 6). Rem Koolhaas: «Architecture has become a total fiction». The Guardian.

Wigley, M. (1988). Arquitectura deconstructivista. Gustavo Gili.

Young, N. M. (2001). Rotating Tower, Dynamic Architecture, world architecture news, architecture jobs. Recuperado 21 de junio de 2014, a partir de http://www. worldarchitecturenews.com/index.php?fuseaction=wanappln.projectview\&upload $\mathrm{id}=10026 \& \mathrm{q}=$ david $\% 20$ fisher 